\title{
Application of different metrics for describing light color quality of a white LED
}

\author{
Robert Supronowicz, ${ }^{* 1}$ Jiajie Fan, ${ }^{2}$ Maciej Listowski, ${ }^{1}$ Adam Watras ${ }^{3}$ and Irena Fryc ${ }^{1}$ \\ ${ }^{1}$ Facultyof Electrical Engineering, BialystokUniversity of Technology, Wiejska 45d, 15-351 Bialystok, \\ ${ }^{2}$ Institute of Future Lighting, Academy for Engineering \& Technology, Fudan University, Shanghai200433, China, \\ ${ }^{3}$ Institute of Low Temperature and Structure Research, Polish Academy of Sciences, Okolna 2, 50-422 Wroclaw.
}

Received April 21, 2021; accepted June 16, 2021; published June 30, 2021

\begin{abstract}
Using an example of UV-excited $\mathrm{Ca}_{9} \mathrm{KMg}\left(\mathrm{PO}_{4}\right)_{7}: 1 \% \mathrm{Eu}^{2+}$ phosphor, there are described methods for characterizing emitted color quality of light at different operating temperatures. The effect is discussed, of adopting two different colorimetric observers established by the International Commission on Illumination (i.e., the CIE 1931 observer with a viewing angle of two degrees and the CIE 2015 observer with a viewing angle of ten degrees) on the position of a chromaticity point of light emitted by phosphor. It was demonstrated that using the CIE 2015 photometric observer to determine the position of a chromaticity point, the tested phosphor is characterized by smaller changes in the color of emitted light as a function of operating temperature rather than when the CIE 1931 observer is used.
\end{abstract}

The pa per characterizes thecolorimetric parameters of $\mathrm{Ca}_{9} \mathrm{KMg}\left(\mathrm{PO}_{4}\right)_{7}: 1 \% \mathrm{Eu}^{2+}$ phosphor synthesized by the citrate method [1] excited by a UV laser diode with a peak wavelength of $375 \mathrm{~nm}$. This kind of phosphor can be used in remote phosphor LEDs. Qualitative and quantitative light parameters are typically characterized using various single-number metrics [2-7] such as CT [K] and CCT [K], LER [1m/W] [8], Ra [-], Rf [-] or using double-digit metrics such as the chromaticity point position $(x, y)$ in the CIE 1931 colorimetric system (Fig. 1), determined from the spectral distribution of radiant power (SPDs) (Fig. 2). These parameters were determined over a range of phosphor temperatures ranging from $250 \mathrm{~K}$ to $425 \mathrm{~K}$ with $25 \mathrm{~K}$ increments. The values of CCT [K], LER [lm/W], $\mathrm{R}_{\mathrm{a}}[-], \mathrm{R}_{\mathrm{f}}[-]$ of the light emitted at these temperatures a re also specified in Fig. 1 . The value of luminous efficacy of a source LES $[1 \mathrm{~m} / \mathrm{W}]$ is not provided at this paper, since this parameter co ncern $\mathrm{s}$ the lighting systems, fixtures or lamps, and the present work concerns the colorimetric properties of phosphor, and not phosphor-based lamps. The values of these parameters prove very good color properties of e mitted light and high luminous efficacy of radiation LER. The color properties of white light sources are commonly described by color temperature $T_{b}(\mathrm{CT})$. However, if the $x y$ chromatic coordinates (Fig. 1) of radiation do not lie on the Planck curve but close to it (in the range of the Judd lines), then we refer to the closest color temperature

\footnotetext{
E-mail: r.supronowicz@doktoranci.pb.edu.pl
}

$T_{c b}(\mathrm{CCT})$. In 1942, in response to the question of whether each point on the CIE 1931 chromaticity diagram corresponds to a different color, it was shown that the color of light is represented by an a rea and notby a poin $t$ on the CIE 1931 dia gram. The shape of a reas of color indistinguishable from the reference color point was called 1-step MacAdam ellipses. The area of the ellip se s varies depending on the a rea of test colors (Fig. 1).

Two light sources with the same CCT value and chromaticity points lying on the opposite sides of the Judd curve will be perceived by humans as differing in color, i.e., one will be perceived as greener and the other as pinkish. When determining the change in chromaticity location point $\Delta u$ ' $v$ ' metrics is applied. This parameter only indicates the magnitude of chromaticity but not it direction. To eliminate this ambiguity [9] ANSI use s the Duv parameter [10] which describes (in the $u v$ colorimetric system) the distance between the chromaticity coordinates of a given light source and the position of a chromaticity point for a Planck source of the sa me color temperature (Fig. 3).

MacAdam ellipses have been deformed after transformation from a CIE XYZ to a CIE LUV sy stem, and they resemble circles with their shape [11]. Information about the direction of emitted light discoloration is provided by the value of the $D u v$ parameter [12]. The ANSI C78.377 standard allows the a pproximation of ellipses to the CIE LUV sy stem u sing circles, where the circle radius of a 1-step ellipse is 0.0011 [13].

Another way of determining the color of a light sou rce is a binning process developed by the manufacturers of light-emitting diodes and carried out according to a specific set of parameters [14]. This process is designed to ensure sorting of LEDs into groups with parameters a s similar as possible to the color of emitted radiation. Currently in practice, the most used binning method is the use of a 2 Degree Standard Observer $\left(2^{\circ}\right)$ in the $x y$ system of CIE 1931 [15]. The North American IESNA/ANSI introduced 10 color quadrants with specific $T_{c b}$, on the 
CIE XYZ dia gram and the CIE LUV diagram ranging from $(2200 \div 6500) \mathrm{K}$. The size of these quadran ts is like how to specify flexible CCT ranges in the scope of the 7-step MacAdam ellipse. This sta ndard also shows

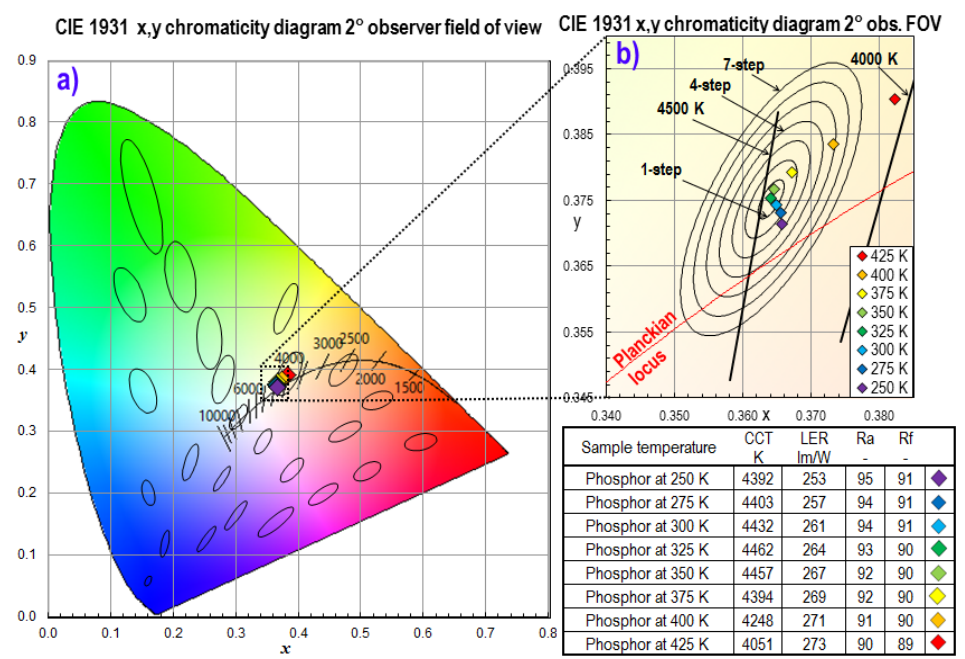

Fig. 1. CIE 1931 chromaticity diagram (a) with the position of $x, y$ chromaticity points of $\left.\mathrm{Ca}_{9} \mathrm{KMg}_{(\mathrm{PO}}\right)_{7}: 1 \% \mathrm{Eu}^{2+}$ phosphor as a function of its temperature and 10-step MacAdam ellipses; (b) enlarged fragment of CIE 1931 diagram with ellipses from step 1 to 7 , where the center of an ellipse was determined for phosphor light at $325 \mathrm{~K}$ ambient temperature. The table summarizes light parameters of phosphor.

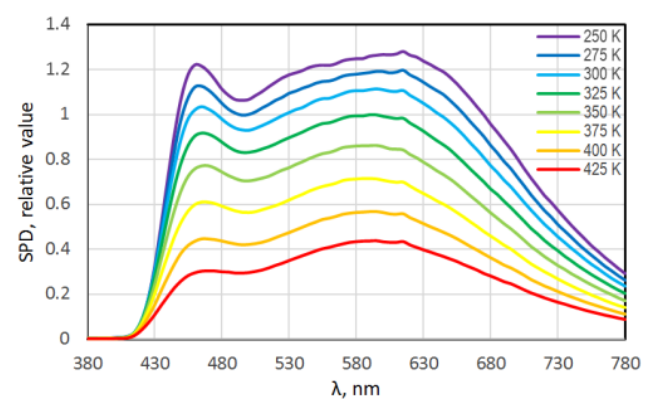

Fig. 2. Relative spectral distribution of the radiant power (SPDs) emitted by the $\mathrm{Ca} 9 \mathrm{KMg}\left(\mathrm{PO}_{4}\right)_{7}: 1 \% \mathrm{Eu}^{2+}$ phosphor excited by $\mathrm{UV}$ radiation $(375 \mathrm{~nm})$.

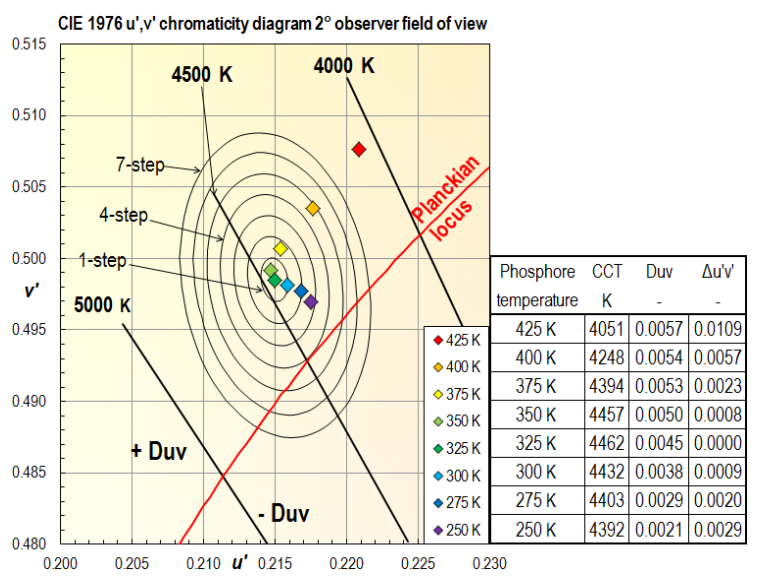

Fig. 3. Chromaticity point position (CIE LUV system) of the phosphor as a function of temperature. The MacAdam ellipses centered at the position of a chromaticity point of phosphor with an operating temperature of $325 \mathrm{~K}$.

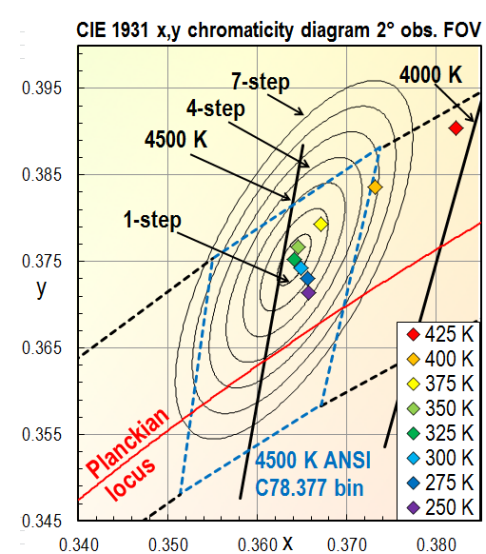

Fig. 4. The quadrant area (blue for CCT 4500K) according to ANSI C78.377.

Manufacturers introduce their individual designations, e.g., by dividing ANSI C78.377 A quadrants into s maller areas - sub-bins (Fig. 5). It should be kept in mind that light sources are subject to binning under certain operating conditions, such as temperature and control current $[16 \div 20]$. Parameters describing color quality a re equally important, i.e., color rendering index $\mathrm{R}_{\mathrm{a}}$; color fidelity index $\mathrm{R}_{\mathrm{f}}$ [21-24].

Nevertheless, occasionally, despite the existing differences in spectral distribution and observed differences in human color perception of this source, LEDs are characterized by the same values of chromaticity point position coordinates for the $2^{\circ}$ colorimetric observer. In view of this fact, the introduction of a colorimetric $10^{\circ} \mathrm{CIE}$ observer (Fig. 6) 
was proposed to characterize the chromaticity point position of LED light. The tra nsition between the $2^{\circ}$ and $10^{\circ}$ observer widens the field of view from $17 \mathrm{~mm}$ to 88 $\mathrm{mm}$ in diameter (for a human eye distance of $0.5 \mathrm{~m}$ ), which allows the determined chromaticity point position to match better the subjective perception of colors.

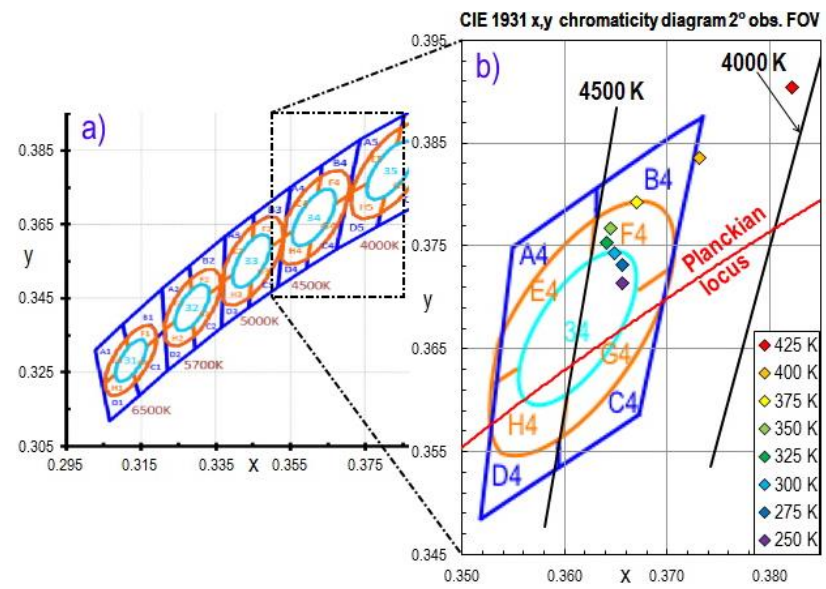

Fig. 5. Representation of (a) an example of ANSI C78.377A quadrilateral bin division into sub-bins in the CIE XYZ system and (b) enlarged fragment of it.

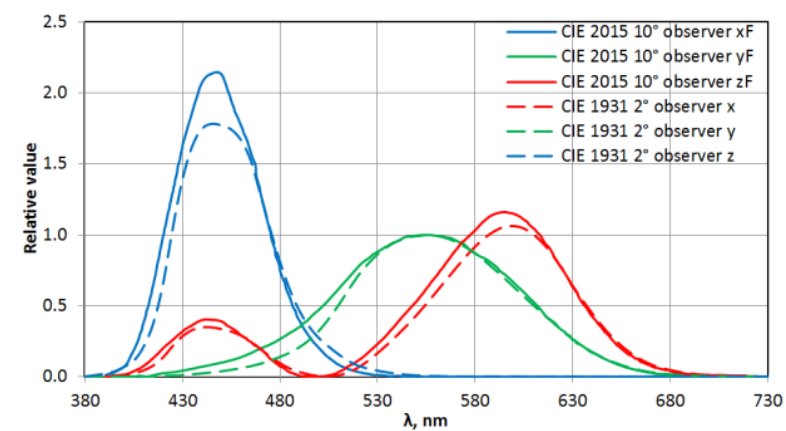

Fig. 6. Values of the trichromatic spectral components for the $2^{\circ} \mathrm{CIE}$ 1931 and $10^{\circ} \mathrm{CIE} 2015$ standard observer [25].

Figure 7 presents the positions of a phosphor chromaticity point as a function of its operating temperature, using a $10^{\circ}$ observer for the calculations.

In the case of developed phosphor, by comparing Fig. 4 and Fig. 7 we can see that, for the considered temperatures of its operation (ambient temperatures), the positions of chromaticity points in the CIE 2015 $x F, 10^{\circ}, y F, 10^{\circ}$ Chromaticity Diagram are located in the 2-step MacAdam ellipse, while for the CIE $1931 x, y$ system they are distributed in the area of the 3 rd ellipse.

Using a CIE XYZ chromaticity diagram based on a $2^{\circ}$ colorimetric observer in the light source binning process can lead to poorer color uniformity in general lighting applications than the $\mathrm{CIE} 2015 x \mathrm{~F}, 10^{\circ}, y \mathrm{~F}, 10^{\circ}$ system where a $10^{\circ}$ observer is used.

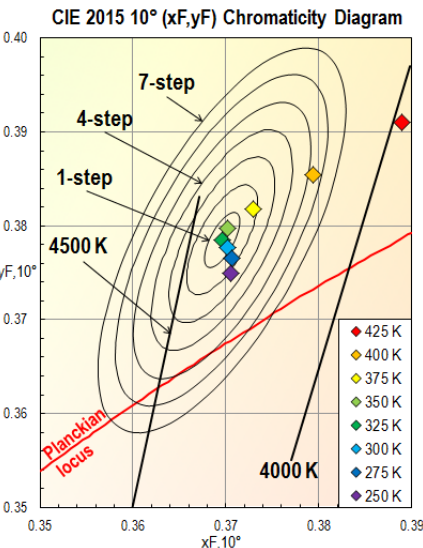

Fig. 7. Position of a phosphor chromaticity point (for the $10^{\circ} \mathrm{CIE} 2015$ colorimetric system observer $(x F, y F)$ as a function of temperature. MacAdam ellipses centered at the position of the chromaticity point of phosphor at an operating temperature of $325 \mathrm{~K}$.

This work was funded by the Ministry of Science and Higher Education in Pola nd at the Bialy stok University of Technology under research subsidy grant number WI/WE-IA/12/2020.

\section{References}

[1] R. Pązik et al., Mat. Resear. Bullet. 48, I.2, 337 (2013).

[2] I. Fryc, S.W. Brown, Y. Ohno, Proc. SPIE 6158, 125 (2006). https://doi.org/10.1117/12.675770

[3] Y. Ohno, LEUKOS, 10:1, 47, (2014)

[4] D. Durmus, Proc. SPIE Vol. 11706, 117061J (2021). doi:10.1117/12.2576421

[5] I. Fryc, D. Czyzewski, Przeglad Elektrotechn. R. 85(11), 276 (2009).

[6] D. Czyzewski, Przeglad Elektrotechn. R. 88(11), 123(2012).

[7] J. Kusznier, W. Wojtkowski, Phot. Lett. Poland 12(1), 16 (2020).

[8] P. Hung, J.Y. Tsao, J. Display Techn. 9(6), 405 (2013).

[9] Y. Asano, MD Fairchild, L. Blondé, PLOS ONE 11(2) e0145671 (2016).

[10] Y. Wang, M. Wei, Lighting Res. Tech. 50(7), 1013 (2018).

[11] K.A.G. Smet, LEUKOS, 16:3, 179 (2020).

[12] D. Petrisor, C.D. Galatanu, C. Haba, L. Breniuc EEEIC/I\&CPS Europe 1, (2019). doi:10.1109/EEEIC.2019.8783310

[13] ANSI C78.377:2017

[14] I. Fryc, T. Dimitrova-Grekow, 2016 IEEE (Lumen V4), 1 (2016). doi:10.1109/LUMENV.2016.7745526

[15] Y. Ohno, Opt. Eng. 44(11), 111302 (2005).

[16] E. Purwanto, P. Dupuis, L. Canale, N. I. Sinisuka, G. Zissis, EEEIC/I\&CPS Europe, 1 (2019). doi: 10.1109/EEEIC.2019.8783248

[17] J. Fan, Y. Li, I. Fryc, C. Qian, X. Fan, G. Zhang, IEEE Photonics Journal, 12(1), 1 (2020). doi:10.1109/JPHOT.2019.2962818

[18] D. Mozyrska, M. Wyrwas, I. Fryc, Przeglad Elektrotechn. R. 93(4a), 232 (2012).

[19] I. Fryc, Przeglad Elektrotechn. R. 86(10), 187 (2010).

[20] I. Fryc, Przeglad Elektrotechn. R. 85(11), 317 (2007).

[21] A. David et al., Opt. Expr. 23, 15888(2015).

[22] S Jost-Boissard, P Avouac, M Fontoynont, Lighting Resear. Technol. 47(7): 769 (2015). doi: 10.1177/1477153514555882

[23] J. Kowalska, Przeglad Elektrotechn. R. 93(6), 50 (2017).

[24] J. Kowalska, I. Fryc, Przeglad Elektrotechn. R. 95(7), 94 (2019).

[25] CIE 170-2:2015 